\title{
(Com)viver em espaços de uma escola sustentável e criativa
}

\author{
Daniela Tomio* \\ Graciele Alice Carvalho Adriano ${ }^{* *}$ \\ Vera Lúcia de Souza e Silva ${ }^{* * *}$
}

\section{Resumo}

O atual contexto histórico social e ambiental requer atitudes formadoras na direção da criação de espaços educadores sustentáveis. Nesta direção, socializamos uma investigação em que objetivamos analisar como se organizam os espaços físicos de uma escola sustentável e criativa em busca de aprimoramento das relações sociais, culturais e com o ambiente natural. A pesquisa foi realizada na EBM Visconde Taunay, Blumenau (SC), escola sustentável e criativa, que em seu coletivo idealizou como projeto pedagógico ser uma Escola Sustentável e que foi certificada como Escola Criativa pela Rede Internacional de Escolas Criativas -RIEC. Para a coleta de dados utilizamos entrevistas formais com a Professora Supervisora do projeto e observação sistemática, documentada com registro fotográfico, a partir de visitas na escola. Para observação empregamos um roteiro com unidades de análise fundamentadas em autores que discutem espaços criativos de aprender na escola e espaços da Educação Ambiental no contexto escolar. As escolas sustentáveis criativas incitam nossas reflexões sobre o modo como as pessoas podem aprender se relacionando de forma ética com o ambiente, consigo e com o outro. Um habitat da escola, espaço que quando sustentável e criativo, integra a participação ativa dos estudantes, professores, gestão e pessoas da comunidade.

Palavras-chave: Escola Sustentável, Escola Criativa, Educação Ambiental, Rede Internacional de Escolas Criativas.

Living in spaces of a sustainable and creative school

\footnotetext{
Professora na graduação e pós-graduação da Universidade Regional de Blumenau, na licenciatura e nos Programas de Pós-graduação Ensino de Ciências Naturais e Matemática (PPGECIM) e Educação (PPGE). Membro da RIEC FURB. E-mail: danitomiobr@gmail.com

** Professora na rede estadual de educação de Santa Catarina, Mestre em Educação pelo Programa de Pósgraduação em Educação (PPGE) da Universidade Regional de Blumenau. E-mail: carvalho.graci@gmail. com

*** Professora na graduação e pós-graduação da Universidade Regional de Blumenau, na licenciatura e no Programa de Pós-graduação Ensino de Ciências Naturais e Matemática (PPGECIM). Coordenadora da RIEC FURB.E-mail: verass@terra.com.br
} 


\begin{abstract}
The current historical social and environmental context requires forming attitudes towards the creation of sustainable educators spaces. In this direction, we socialize an investigation that aimed to analyze how to organize the physical space of sustainable and creative school seeking enhancement of social, cultural and natural environment. The survey was conducted in a public school called Viscount Taunay in Blumenau (SC). It is a sustainable and creative school, which in its collective conceived as a pedagogical project being a Sustainable School and it was certified as a Creative School by the International Network of Creative-RIEC Schools. To collect the data, we used formal interviews with the Supervisory Teacher of the project and systematic observation, documented with photographic record from the school visits. To the observation, we used a script with units of analysis based on authors who discuss creative spaces to learn in school and areas of environmental education in the school context. Creative sustainable schools encourage our reflections on how people can learn relating in an ethical manner with the environment and with each other. A school habitat, when it is a sustainable and creative space, it integrates the active participation of students, teachers, school management and community members.
\end{abstract}

Keywords: Sustainable School, Creative School, Environmental Education, International Network of Creative Schools.

Introdução

Escolas criativas têm por finalidade contribuir para uma educação atenta às necessidades presentes do século XXI, estimulando o desenvolvimento da consciência, de valores e da criatividade (TORRE; ZWIEREWICZ, 2009). Seguindo este princípio, existem algumas instituições de ensino que priorizam processos de ensinar inovadores e criativos, para promover uma educação transformadora baseada em valores, potenciais humanos e habilidades para vida.

Nesta direção, podemos destacar as escolas sustentáveis. Estas preconizam o discurso e atitude na perspectiva de estimular o conhecimento, compromisso e participação efetiva da comunidade escolar, a responsabilidade e o exercício consciente da cidadania, o diálogo, empatia, companheirismo, apoio, interação e senso de coletividade. Trazem em seu cerne aspectos que se relacionam e se complementam entre o cuidado, integridade e diálogo. Transformar uma escola em um espaço sustentável implica romper com a lógica que orienta a dinâmica atual, da mesma forma que valorize a coletividade, colaboração, ações cooperativas e criativas, como uma mudança no cenário da educação.

As escolas sustentáveis como incubadoras de inovações, necessitam atrelar suas pretensões ao currículo, à gestão e ao espaço físico. Nesta direção, nosso objeto de 
interesse na pesquisa foi analisar a dimensão do espaço físico. Com isso, não desvalorizamos as dimensões do currículo e da gestão, mas pressupomos que a organização criativa dos espaços físicos na escola, considerando aspectos da sustentabilidade, modificam e motivam novas (inter)relações do coletivo da escola entre as pessoas, com as outras espécies no e com o meio ambiente. Desse modo, partilhamos do entendimento de que um espaço físico pode contribuir para o cuidar e o educar com as edificações e o entorno natural, valorizados e projetados para proporcionar melhores condições de aprendizado e convívio social. Espaços físicos com edifícios com maior conforto térmico e acústico, eficiência energética, uso racional da água, destinação dos resíduos de forma adequada e acessibilidade facilitada podem favorecer atitudes sustentáveis. (BRASIL, 2012).

Com a proposta de investigar pesquisas sobre o tema escolas sustentáveis a organização dos seus espaços físicos observamos, por meio de um levantamento do estado da arte no portal de teses e dissertações da CAPES até o ano de 2015, uma ênfase em estudos referentes à arquitetura, porém isentas de uma discussão das suas relações com o aspecto educativo. Compartilhamos com Rinaldi (2012) do entendimento de que há uma necessidade dos profissionais na educação expandirem e aprofundarem conhecimentos dos espaços físicos da escola, concebendo-os como constitutivos das experiências de aprendizagem e de novas relações culturais daqueles que os habitam. Isso evidencia a necessidade de observação do uso que os sujeitos da escola fazem dos ambientes.

Para isso observamos iniciativas, como uma da Secretaria de Educação Continuada, Alfabetização, Diversidade e Inclusão que instituiu um manual com orientações para apoiar a implementação de projetos de pesquisa e intervenção em escolas da educação básica: "Vamos cuidar do Brasil com escolas sustentáveis" (BRASIL, 2012). Ainda, nos inspiramos na relação que Legan (2010) faz da escola como "habitats" e nas discussões de Rinaldi (2012) sobre os espaços de aprender para infância.

Com base nestas reflexões, elaboramos uma pesquisa com o objetivo de analisar como se organizam os espaços físicos de uma escola sustentável e criativa em busca de aprimoramento da criatividade nas relações sociais, culturais e com o ambiente natural de sua comunidade.

Este estudo foi elaborado em uma ação colaborativa entre docentes-pesquisadores da pós-graduação e os programas de extensão "Educação em Ciências para o século XXI” e a “ Rede de Escolas Criativas - RIEC FURB” da Universidade Regional de Blumenau. Uma versão inicial dessa pesquisa foi divulgada no XXI Congresso Nacional de Educação. (ADRIANO, TOMIO, 2015). 
Para socializar a pesquisa inicialmente apresentamos conceitos que sustentam nossas interpretações, na sequência descrevemos o percurso metodológico e o contexto investigado. Por conseguinte são descritas as informações produzidas no estudo e, por último, as considerações finais.

\section{Espaços educadores sustentáveis e criativos}

Vivemos um tempo em que os problemas socioambientais nos desafiam à sensibilidade, a elaborar novos conhecimentos e valores, a valorizar também os conhecimentos de antigas tradições em suas relações com a natureza, a usar a criatividade, a aumentar a nossa capacidade de autoconhecimento e de participação, de forma colaborativa e responsável, para decidir sobre o presente e o futuro em uma sociedade sustentável. Neste contexto, surge o desafio para escola em se constituir um espaço e um tempo de convivência que possibilite aos seus sujeitos de diversidades percursos formativos significativos, contribuindo-lhes para uma formação integral e integrada com a natureza e as outras dimensões do meio ambiente. (TOMIO, 2016).

No Brasil, experiências nesta direção organizam-se a partir de um projeto de “escola sustentável”, legitimado com o Decreto n 7.083/2010, e que inicia fazendo parte no contexto da Educação Integral e do Programa Mais Educação. Como destacam Trajber e Sato (2010, p. 72 ):

O projeto é uma intervenção de políticas públicas, geradora de transformações face à emergência das mudanças socioambientais globais, e acata as orientações da Avaliação Ecossistêmica do Milênio e do Tratado de Educação Ambiental para Sociedades Sustentáveis e Responsabilidade Global, entre outros importantes documentos e movimentos ambientalistas locais, nacionais e mundiais.

Nesta direção, a Educação Ambiental passa a ser um projeto de escola conectado com premissas locais e globais para as relações com e no meio ambiente. É mais que desenvolver projetos de coleta seletiva de resíduos sólidos ou arborizar a escola, por exemplo. A escola sustentável se constitui com uma mudança na cultura do coletivo na perspectiva de uma sociedade sustentável. É lugar de emancipação de seus estudantes, professores, demais profissionais da Educação, estendendo à sua comunidade e seus territórios.

[Uma escola sustentável] Trata-se de um local onde se desenvolvem processos educativos permanentes e continuados, capazes de sensibilizar o indivíduo e a coletividade para a construção de conhecimentos, valores, habilidades, atitudes e competências voltadas para a construção de uma sociedade de direitos, ambientalmente justa 
e sustentável. Uma escola sustentável é também uma escola inclusiva, que respeita os direitos humanos e a qualidade de vida e que valoriza a diversidade. (BRASIL, 2012, p. 10)

Para isso, há a necessidade de se pensar no projeto da escola três dimensões que estão inter-relacionadas: o espaço físico, a gestão e o currículo. O espaço físico em uma arquitetura composta de conforto térmico e acústico, com acessibilidade, gestão eficiente de água e energia, saneamento e destinação adequada dos resíduos. Ainda, que promova a integração e a diminuição de interferências com o ambiente natural de seu interior e entorno. Uma gestão que compartilhe o planejamento e decisões sobre a rotina escolar, juntamente com a comunidade, respeitando os direitos humanos, a diversidade cultural, étnico-racial e de gênero. Um currículo que comporte a inclusão de conhecimentos, saberes e práticas sustentáveis no Projeto Político Pedagógico (PPP), contextualizado na realidade local e estabeleça vínculos com a sociedade global. $\mathrm{O}$ Projeto Político Pedagógico (PPP) como documento orientador das ações escolares, construído de forma dinâmica, com a participação da comunidade escolar engajada em definir os objetivos, a finalidade do trabalho educativo (BRASIL, 2009).

Pressupomos que (com) viver em uma escola sustentável possibilita intenções pedagógicas que favoreçam a integração do ser com ele mesmo, com seus pares e com o meio a partir de experiências criativas. Com base na Ata de Constituição da RIEC (ESPANHA, 2012), entendemos as escolas criativas como aquelas instituições educativas que vão além do ponto de partida (transcendem), que dão mais do que têm e vão além do que se espera (recriam), que reconhecem o melhor de seus estudantes e professores (valorizam), que crescem por dentro e por fora buscando por tudo, a qualidade e a melhora (transformam). Em outras palavras, esses centros desenvolvem os potenciais criativos dos estudantes, os valores humanos, os sociais, os de convivência, os de liberdade e criatividade, as habilidades para a vida, a iniciativa e empreendedorismo, dando importância ao desenvolvimento humano e ambiental sustentável e tentando sempre compatibilizar conhecimento com reconhecimento Compartilham um olhar transdisciplinar e ecoformador. Resumindo, instituições vivas que transcendem, recriam, valorizam e transformam. Estes são os quatro pontos cardiais que orientam as instituições criativas (TORRE; SILVA, 2015).

Com foco na reflexão de uma escola criativa e sustentável destacamos, neste estudo, a dimensão de seus espaços físicos, aqui denominados espaços educadores sustentáveis, de acordo com a Série Cadernos Pedagógicos Mais Educação, Educação Ambiental: 
[...] são aqueles que têm a intencionalidade pedagógica de se constituir em referências de sustentabilidade socioambiental, isto é, espaços que mantenham uma relação equilibrada com o meio ambiente; compensam seus impactos com o desenvolvimento de tecnologias apropriadas, permitindo assim qualidade de vida para as gerações presentes e futuras (BRASIL, 2009, p. 07).

Os espaços educadores sustentáveis são concebidos como lugares onde o coletivo da escola constrói seus conhecimentos, identidades e histórias, comportam tanto o virtual quanto o real. Espaços que revelam a forma de conceber a educação, o indivíduo e as relações deste com os outros e com o meio.

\section{Procedimentos metodológicos}

Como base nos pressupostos enunciados sobre a nossa compreensão que compartilhamos de "espaços educadores sustentáveis" apresentamos o percurso investigativo da pesquisa nas próximas seções.

\section{O "lugar" da escola}

A pesquisa foi realizada na EBM Visconde Taunay, uma escola pública da rede municipal, do ensino fundamental, localizada na cidade de Blumenau (SC), que em seu coletivo idealizou como projeto pedagógico ser uma Escola Sustentável. A escola conta atualmente 850 alunos matriculados de $1^{\circ}$ ao $9^{\circ}$ anos, período do ensino fundamental, 70 funcionários que compõem a comunidade escolar interna. Situada no bairro Itoupava Central, região Norte do município de Blumenau, apresenta como área urbana ocupada de $44,67 \mathrm{~km}^{2}$. A maior parte da população se dedica aos setores da indústria, comércio e prestação de serviços, com algumas famílias que praticam a agropecuária de subsistência com a comercialização dos excedentes. Nas extremidades do bairro, nos vales há atividade rural agrícola com o plantio de banana, milho, aipim, mandioca e outras culturas, a pecuária formada pela criação de bovinos, suínos e gado de leite (BLUMENAU, 2016).

Muitas das ações propostas no Projeto Político Pedagógico são desenvolvidas com a parceria de órgãos, instituições e colaboradores da escola. Desta forma, o projeto pretende orientar a organização coletiva do trabalho pedagógico, estabelecendo as prioridades, possibilitando relações para o bom desenvolvimento das atividades escolares e avaliando os pontos que necessitam de esforços para atingir os objetivos. 
A escola deseja o compromisso com a formação integral dos estudantes, direito a boa educação, ética, respeito e ao desenvolvimento da plena cidadania (EBM VISCONDE DE TAUNAY, 2013).

No ano de 2013 a escola recebeu o certificado de Escola Criativa e faz parte de um grupo restrito, com quatro escolas do Brasil, que possuem esse título concedido pela Rede Internacional de Escolas Criativas (RIEC), com sede na Universidade de Barcelona, na Espanha. A escola alcançou esse título devido seus trabalhos de sustentabilidade desenvolvendo potenciais criativos de seus alunos e professores. Com isso a escola teve maior reconhecimento do seu trabalho e tem se tornado um espaço de inspiração para pesquisa e trabalhos de formação de professores de universidades da região (VIEIRA, TOMIO, PUKALL, 2014).

\section{Percurso investigativo}

Para produção de dados na pesquisa, empregaram-se entrevistas com a Professora Supervisora do projeto na Escola e observação sistemática, documentada com registro fotográfico, a partir de visitas na escola. Para observação, empregou-se um roteiro com unidades de análise com autores que discutem espaços de aprender na escola (GANDINI, 1999; RINALDI, 2012; CEPPI; ZINI, 2013) e espaços da Educação Ambiental no contexto escolar (LEGAN, 2010; BRASIL, 2012). Na figura 1 apresenta-se o roteiro, sistematizado por Adriano e Tomio (2015), que utilizamos para registrar aspectos observados no decorrer das observações sobre os espaços:

Fig. 1- Roteiro de observação

\begin{tabular}{|l|l|l|}
\hline Espaços & Descrição & Observações na Escola \\
\hline $\begin{array}{l}\text { Espaços de convivência e cultura que } \\
\text { possibilitam e favorecem: a mobilidade, } \\
\text { acessibilidade, organização e partilhamen- } \\
\text { to do conhecimento com diferentes mani- } \\
\text { festações. }\end{array}$ & & \\
\hline $\begin{array}{l}\text { Espaços como conteúdos educacionais: } \\
\text { que contem mensagens educacionais car- } \\
\text { regadas de estímulos para a experiência } \\
\text { interativa e aprendizagem construtiva. }\end{array}$ & & \\
\hline
\end{tabular}




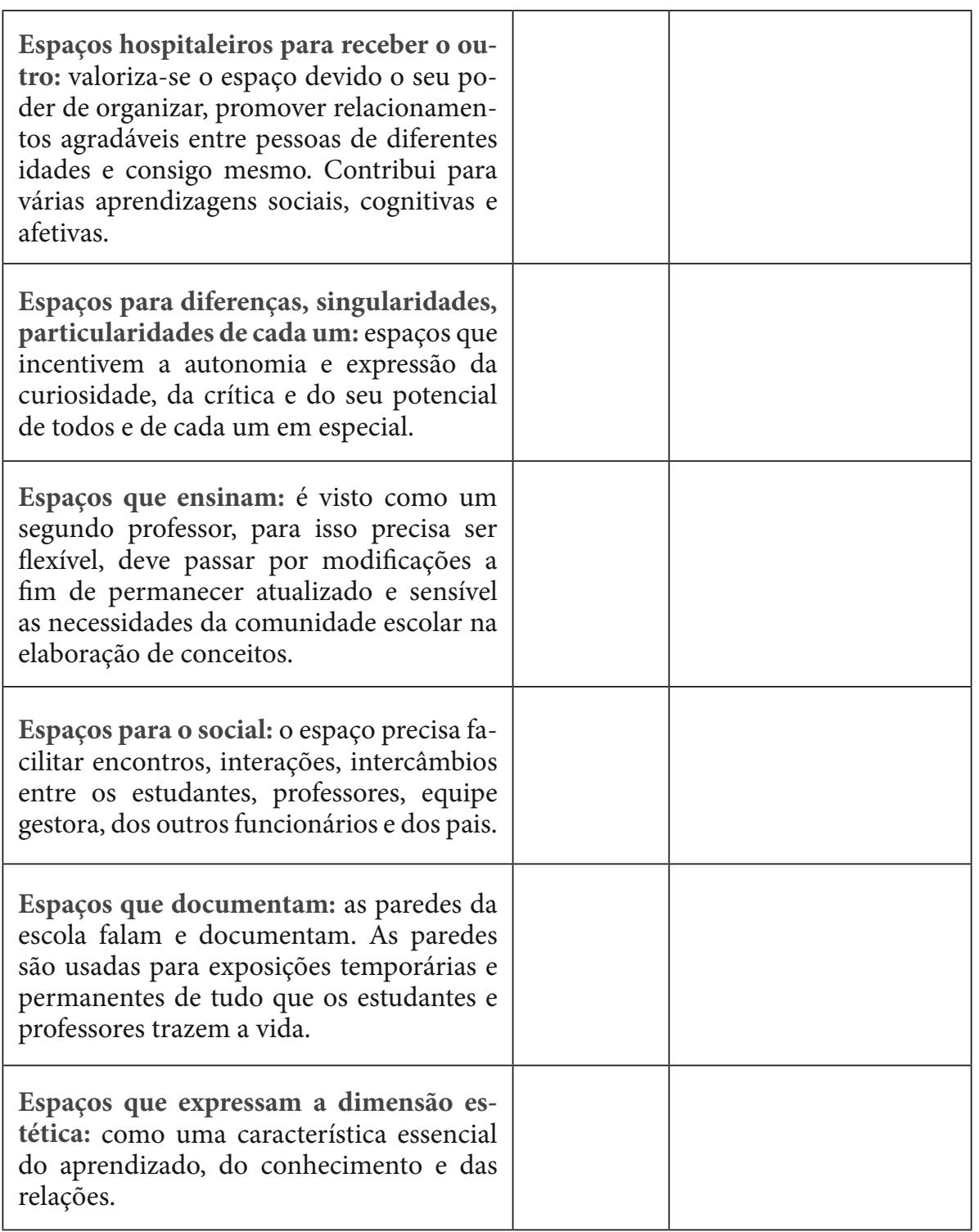

Fonte: Adriano e Tomio (2015) 


\section{A escola e seus espaços educadores sustentáveis}

Os dados elaborados na investigação foram sistematizados na sequência, considerando um caminho pela escola a fim de "guiar o leitor" pelos seus espaços de aprender.

Entrando na escola - espaço hospitaleiro, para receber o outro

$\mathrm{Na}$ entrada um banco que permite o descanso ou a espera por alguém. Quando chegamos na escola observamos um espaço que recebe e acolhe aqueles que circulam na entrada da instituição escolar. Espaço que organiza, como apresentam Edwards, Gandini (2005) que promove relacionamentos entre as pessoas de diferentes idades, tempos para conhecer o outro, pensar quando estiver só a espera de algo ou alguém. Momentos que possibilitam aprendizagens sociais, cognitivas e afetivas.

Um cuidado na organização do espaço com o intuito de educar toda a comunidade para o descarte de materiais. Quem chega já tem oportunidade de refletir com o coletivo da escola sobre o destino de seus resíduos. Há locais para a coleta das pilhas e baterias, óleo comestível, lacres de latinha de alumínio e lâmpadas, que são acondicionadas em caixas e galões para o recolhimento e destino. A comunidade escolar possui acesso a esses recipientes e depositam o lixo que será submetido a processos químicos ou industriais, para o devido fim, reduzindo o consumo de mais matéria prima na produção de novos materiais.

$\mathrm{Na}$ entrada há um espaço para a comunidade divulgar os classificados como venda, aluguel ou procura-se, possibilitando uma interação com os fatos que ocorrem no entorno da escola. As famílias e frequentadores do espaço escolar integram suas vivências ao de aprendizagem, percebemos uma preocupação em utilizar este local como uma oportunidade de integração entre a comunidade escolar interna e a externa. Rinaldi (2012) salienta que a relação entre o indivíduo e seu habitat são recíprocas, ambos são ativos e modificam-se. Assim, tanto as pessoas que circulam pelo hall de entrada, que fazem parte de forma direta ou indiretamente da comunidade escolar, modificam o espaço e são também influenciados. Desde colocar uma caixa para recolher pilhas usadas a proporcionar um espaço para divulgação de compra e venda, infere mensagens que se não pertencem ao meu cotidiano, remetem a reflexões e possíveis mudanças de atitudes ao serem compartilhadas. 
Fig 2 - Entrada da escola
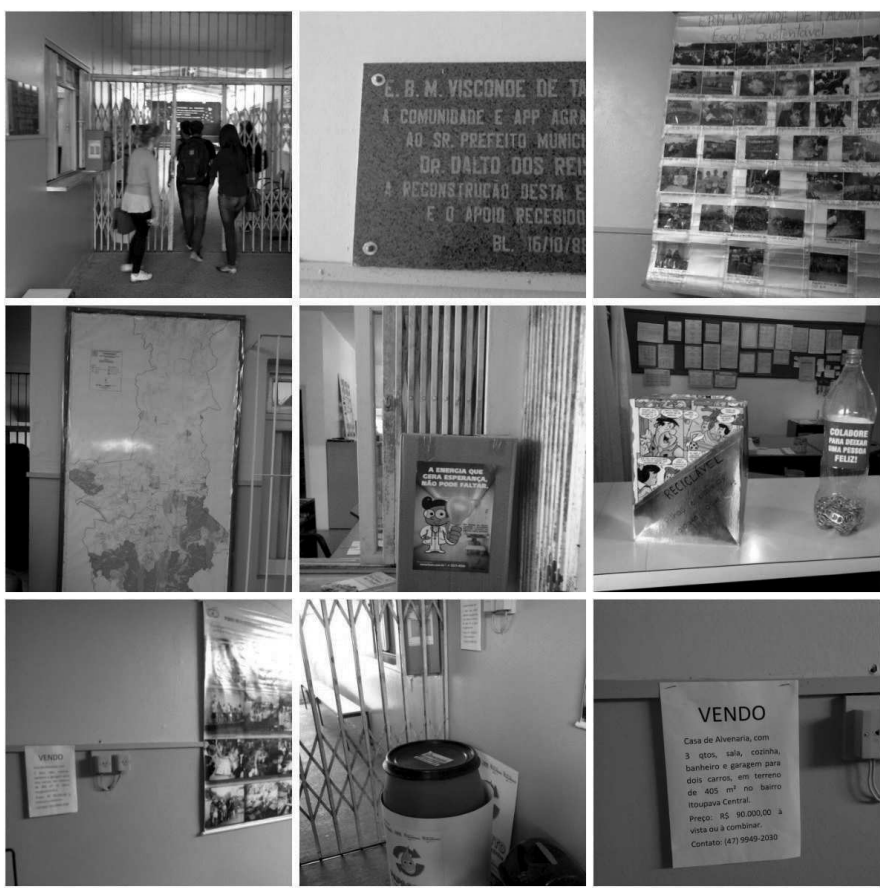

a) Entrada; b) Marco de sua história; c) Mural de fotos e fatos da escola; d) Mapa de localização da escola no Bairro; e) Caixa coletora de lâmpadas; f) Caixa coletora de pilhas e garrafa pet para lacres de latinha de alumínio; g) Parede da entrada com mural de fotos e avisos; h) Tambor para coleta de óleo de cozinha usado; i) Cartaz da comunidade indicando classificados. Fonte: Arquivo das autoras

\section{As paredes da escola: espaços que documentam}

As paredes da escola documentam de forma intrínseca pensamentos e vontades das pessoas que circulam no espaço, que fazem parte da história local. No hall de entrada as paredes documentam os eventos, em murais de caixinhas de leite reaproveitadas, costurados pelas mãos da costureira funcionária da escola, evidenciam as atividades desenvolvidas com os estudantes.

As exposições auxiliam os professores na avaliação dos resultados de seus trabalhos, contribuindo para reflexões e o próprio avanço profissional (EDWARDS; GANDINI; FORMAN, 2005). As exposições dos materiais produzidos pelos estudantes e professores, oferecem documentação sobre atividades específicas, que traduzem 
o enfoque educacional da escola. Consistem em um modo de transmitir aos que circulam no espaço escolar o potencial dos estudantes, suas capacidades e criatividade em desenvolvimento e o que acontece na escola. Acrescenta-se ainda, a consideração que os adultos apresentam em relação à produção das crianças e adolescentes ao divulgar nas paredes as suas atividades.

Fig. 3 - Paredes da escola
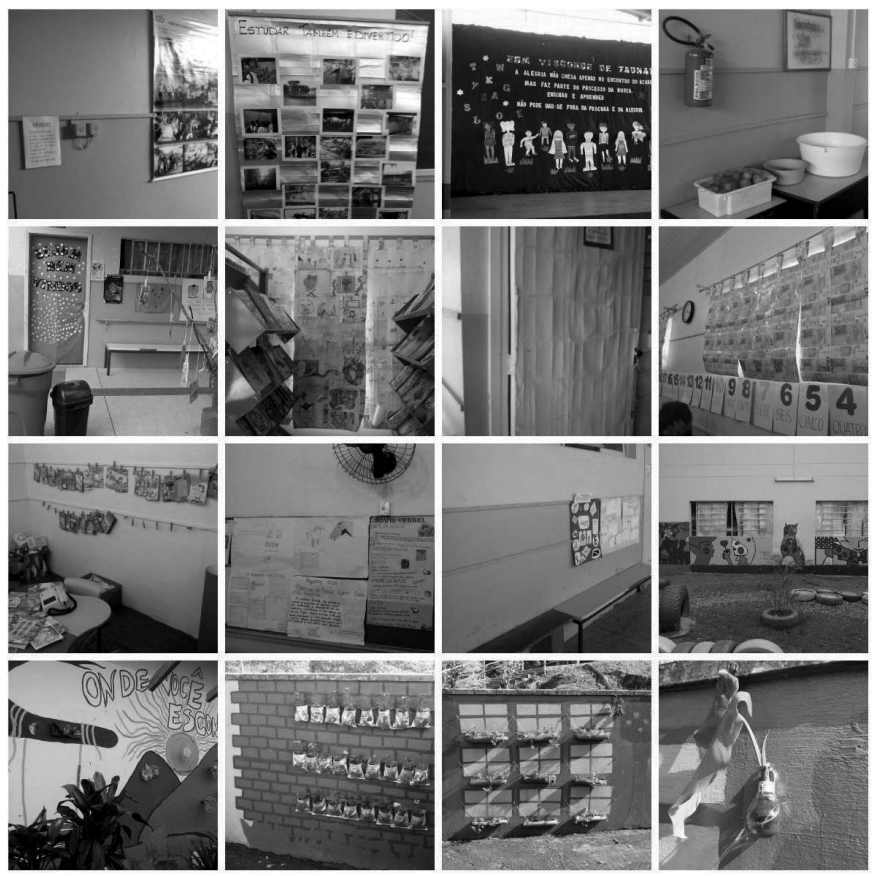

a) Entrada; b) Mural confeccionado com caixa de leite com fotos e fatos da escola; d) Painel no pátio interno; e) Lanche dos estudantes; f) Entrada da biblioteca; g) Cortinas confeccionadas com caixas de leite; i) Porta da sala de aula revestida com caixa de leite pintada; j) Cortinas da sala de aula confeccionada com caixa de leite; h) Exposição dos trabalhos dos estudantes parte interna da sala de aula; k) Exposição dos trabalhos dos estudantes parte interna da sala de aula; 1) Exposição dos trabalhos dos estudantes parte externa da sala de aula, $m$ ) Pintura nas paredes do parque; n) Parede organizada pelos bolsistas PIBID e estudantes sobre o destino do lixo; o) Reaproveitamento da parte interna de alumínio do café como vasos; $p$ ) Reaproveitamento de garrafa pet como vasos; q) Reaproveitamento de lâmpada como vaso. Fonte: Arquivo das autoras

No acesso da escada para as quadras, duas paredes foram organizadas, uma utilizando garrafas pets e outra a embalagem de alumínio interna da caixa de café, 
para o plantio de flores. Decoração que deu vida ao muro que serve de contenção do terreno com uma subida íngreme, entrecortada por uma escada. Um foco de lâmpada reaproveitado serve de abrigo a uma planta, pendurado no muro, que acompanha as pets em flor. Rinaldi (2012) lembra que a linguagem do espaço constitui um fator condicionante, explícito e reconhecível, percebível e interpretado por todos desde jovens. Observamos os espaços que frequentamos, as paredes, os objetos dispostos no lugar, emitimos opiniões de valor e adjetivos, ás vezes favoráveis outras não. Imagens fotografadas pelas lentes de olhos atentos que registram impressões dos lugares, assim como os estudantes o fazem no percurso dos anos escolares.

As paredes, pintadas de branco, que também auxilia na redução da temperatura, abrigam os trabalhos expostos em painéis, varais com informações de acordo com os estudos da turma. As cortinas das salas de aula confeccionadas com caixas de leite foram pintadas de branco e auxiliam na excessiva entrada de luz e calor.

Os estudantes ao observarem o contexto escolar, vivenciam a proposta da Escola Sustentável impressa nas paredes, podem interiorizar formas de pensar que refletirão no agir. Participam das escolhas e elaborações, fazem parte ativamente da comunidade escolar, vivenciando uma forma de pensar o mundo sustentavelmente.

\section{Pátio, bosque, hortas: espaço para o social e espaços de convivência e cultura}

Durante as observações, percebemos espaços que propiciam interações sociais entre os estudantes, professores e as diversas espécies que habitam o meio. Nos corredores da escola há bancos distribuídos para que os estudantes possam sentar, conversar, ler os livros, ou mesmo descansarem observando as árvores plantadas no pátio, as flores em pequenos jardins, montados em pneus reutilizados e coloridos, distribuídos ao redor das árvores e em encontro as paredes do prédio.

Em um corredor com uma parede que forma um acesso limitado de passagem foi organizado com mesas e cadeiras um pequeno espaço de estudos, um quadro negro pintado na parede permite a escrita dos estudantes. O pátio com amplo espaço oferece a liberdade das brincadeiras infantis, a casa construída coletivamente com garrafas pets com propósito de ser um futuro local de contação de histórias, já abriga algumas crianças que fazem uso no momento do recreio para interações sociais. O futuro se fazendo presente aos olhos da criatividade infantil.

Espaços que abrigam outras formas de viver e que são acompanhadas pelos olhares de quem conhecem seus significados. A horta mandala elaborada pelos professores e estudantes, divide em sua constituição, territórios que pertencem a cada ano do 
Ensino Fundamental. Os estudantes semeiam e observam o crescimento das plantas, adubam com o que resulta da composteira. Participam do crescimento e das decisões acerca da organização e plantio no espaço, o que também configura o trabalho do professor de educação física, que elaborou uma horta, próximo as escadas de acesso as quadras. Nesta horta, os estudantes nos momentos de educação física, cuidam e verificam o crescimento das plantas. Possuem o aval do professor em solicitar as verduras e legumes plantados, para serem consumidos com a família em casa. Uma horta comunitária no espaço da comunidade escolar, que leva as famílias conhecimentos produzidos pelos estudantes, histórias sobre o plantio e manutenção das hortaliças. Neste espaço, há uma composteira elaborada em um galão de cinco litros, que serve para os estudantes analisarem experimentalmente a decomposição das cascas produzidas em um lanche, uma vez que uma grande está sendo construída na escola.

Através de atividades compartilhadas, do diálogo, da cooperação os estudantes constroem em conjunto o conhecimento de mundo, de sociedade. O desenvolvimento social consiste em uma parte intrínseca do desenvolvimento cognitivo, onde o espaço figura uma organização facilitador de encontros, interações e intercâmbios (EDWARD; GANDINI; FORMAN, 2005).

Fig. 4- Pátio, bosque e hortas

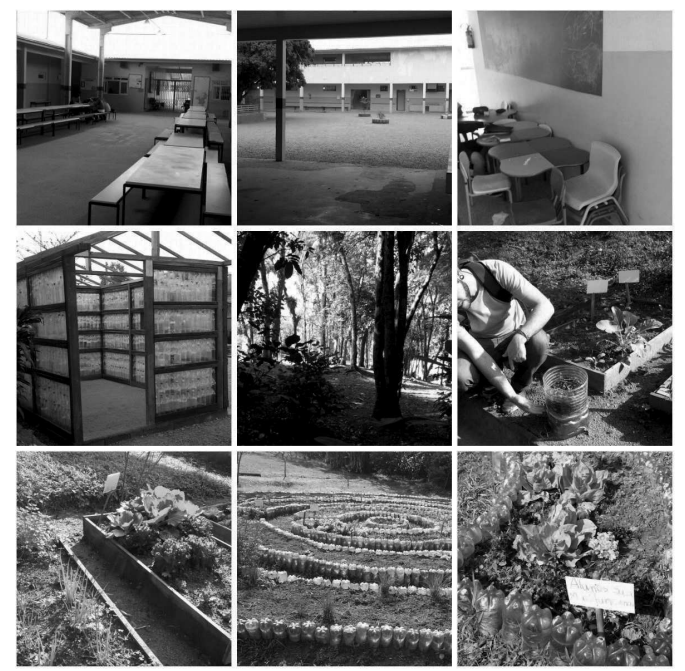

a) Área interna do pátio; b) Área externa do pátio; c) Corredor na escola; d) Casinha da leitura confeccionada com pets; e) Bosque; f) mini- composteira; g) Horta; h e i) Horta mandala. Fonte: Arquivo das autoras 
Biblioteca e atelier de costura: espaço para diferenças, singularidades, particularidades de cada um

Um dos espaços que nos chamou a atenção consiste no atelier, uma sala com máquinas de costura, armários e mesas, onde a costureira cria produções com materiais reciclados. Bolsas, pastas, envelopes e painéis com caixas de leite coletadas são utilizadas pela comunidade escolar, auxiliando no modo de conceber a reutilização dos materiais, influenciando na economia dos recursos financeiros da escola, e dos bens naturais. Os materiais produzidos recebem sentido no uso pelos docentes com os estudantes, onde guardam os trabalhos nas pastas. Os jogos e as letras utilizadas nos anos iniciais do Ensino Fundamental são guardados nos envelopes. As bolsas transitam com diversos materiais da escola, inclusive algumas são ocupadas no projeto 'sacola viajante' desenvolvido pela professora que ocupa a função de bibliotecária. Uma vez na semana uma criança de cada turma, dos anos iniciais do Ensino Fundamental, leva a sacola para casa com um livro de história infantil durante o final de semana. Após a leitura com a família, o preenchimento de uma ficha de leitura, com o desenho realizado no caderno da 'sacola viajante', o estudante conta a história para a turma no espaço da biblioteca. Momentos de partilha de experiências e encantamentos com conhecimentos que são construídos de forma oral, no imaginário. Percepções de sentimentos, sentidos, valores e opiniões, discutidos com a turma quando a contação da história termina. 
Fig. 5 -Biblioteca e atelier de costura
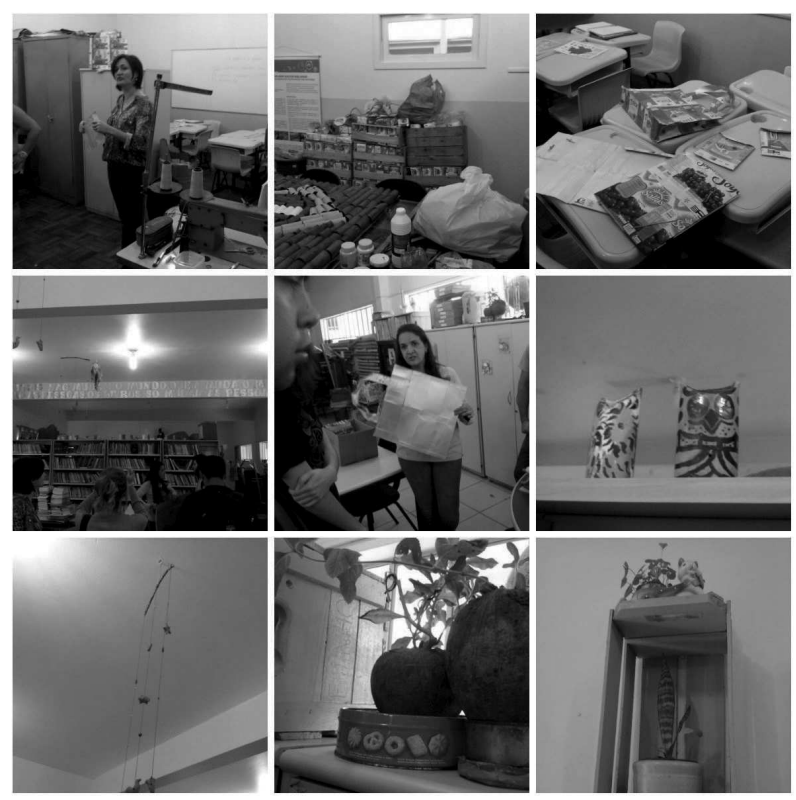

a) Sala do atelier; b) Materiais para reutilização na sala do atelier; c) Materiais produzidos com a reutilização das caixas de leite; d) Parte interna da Biblioteca; e) Explicação da bibliotecária sobre o uso da sacola ecológica confeccionada no atelier; f) Corujas confeccionadas com a parte interna dos rolos de papel higiênico; g) Móbile com argila; h) Reutilização de coco para vaso; i) Reutilização de caixa de fruta como estante. Fonte: Arquivo das autoras

As trajetórias e os processos de aprendizado dos estudantes modificam na interação com os contextos culturais e escolares, na medida que forma um 'ambiente formador', um espaço para o desenvolvimento desses processos. A competência e a motivação dos estudantes varia conforme o estímulo motivacional do contexto circundante (RINALDI, 2012).

A biblioteca se revelou também um espaço de sustentabilidade. Em cada canto um encanto, uma forma de reutilizar os recursos que em outro momento já fizeram parte do meio ambiente, mas de outra forma. Dobraduras realizadas com os estudantes, rolinhos de papel higiênico que se transformam em aves e animais de fantoche, caixas de frutas pintadas que expõem os livros, guardam documentos e papéis da biblioteca. Espaço caracterizado por elementos que apresentam uma forma de se orga- 
nizar reutilizando materiais, resignificando utilidades, principalmente considerando as produções dos estudantes em meio das obras de autores dos livros. As cortinas elaboradas com caixas de leite entregues pela comunidade escolar servem de expositores para os desenhos dos herdeiros que desde pequenos aprendem a viver reaproveitando o que muitos descartam. Vivenciam conceitos expressos na proposta da Escola Sustentável, conceitos que se transformam em prática.

Salas de aula, quadra de esportes: espaço como tendo conteúdos educacionais

Nas salas de aula observamos um espaço organizado de forma semelhante a inúmeras outras salas, com alguns diferenciais. Apesar da familiaridade da disposição da mobília, quadro, armários, mesa da professor, existem detalhes que a diferenciam. Em cima de uma mesa para a acesso da turma, há uma caixa que recolhe as aparas dos lápis, lascas de madeira que serão utilizadas na caixa de compostagem e nas atividades escolares, outra com as sobras de giz de cera como material coletivo de uso finito. Uma cesta confeccionada com jornal comporta materiais diversos para uso nas atividades propostas com os estudantes, estes possuem acesso e auxiliam na organização do espaço da sala. Ainda, combinado com os estudantes há uma caixa de papelão que armazena folhas de caderno que podem ser reutilizadas para rascunhos.

A sala multifuncional frequentada por estudantes que necessitam de um atendimento especializado ocorre extraclasse. Nesta sala encontram-se painéis confeccionados com caixas de leite, um em formato de envelopes que guardam informações quanto ao dia, mês, ano, sentimentos e nomes dos matriculados nas turmas de atendimento. Há computadores, espelho e materiais alternativos acondicionados em latões e caixas, o lixeiro consiste no reaproveitamento de jornal, trançado em formato de cesta. Neste espaço promove-se a ampliação da inclusão social do estudante, ao mesmo tempo em que ele vivencia a cultura da sustentabilidade.

Espaços que ensinam, silenciosos, influenciam formas de pensar e de conceber o mundo. O 'terceiro educador' (RINALDI, 2012), para além do trabalho mediativo de aprendizagem do professor, outra forma de se aprender. Os estudantes observam e aprendem desde cedo com e no meio. A organização dos espaços na sala, o cuidado com os materiais, a ação do professor como adulto educador, influencia as ações dos estudantes, indivíduos em fase de desenvolvimento e aprendizagem social. Assim, como espelhos, acabam refletindo em suas ações o que observam no outro, constroem seus conhecimentos na observação, no entendimento que fazem do mundo, dos conhecimentos científicos apresentados pela escola. 
A sala de música recebe os estudantes em aulas extra-classe, que formam a fanfarra da escola. As aulas de educação física são oferecidas nas quadras cobertas com acesso pelas escadas ou no campo de futebol com amplo gramado, onde habitam pássaros com seus ninhos. As quadras oferecem mesas de tênis de mesa, redes de vôlei e cestas de basquete, opções que permitem ao professor desenvolver um planejamento variado, com materiais próprios a cada modalidade esportiva.

Fig. 6 -Salas de aula, quadra de esportes
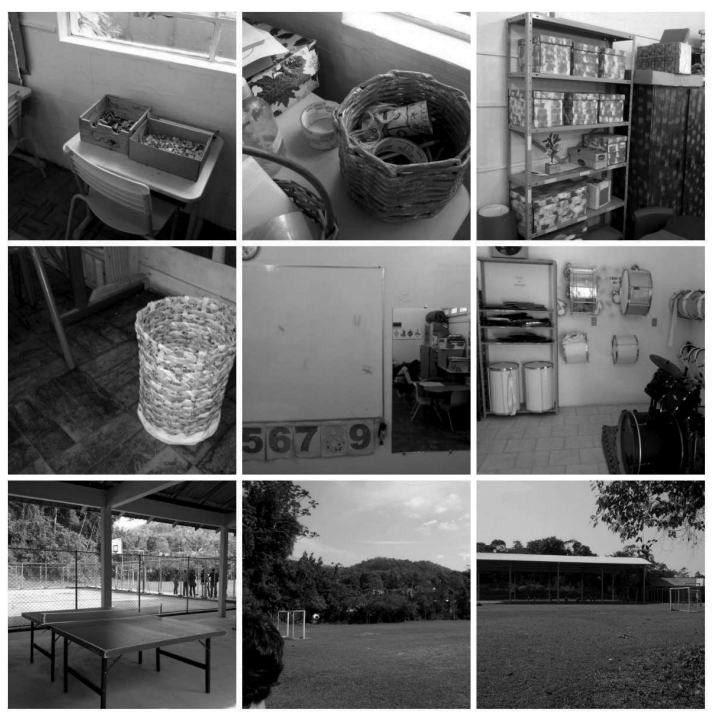

a) Caixa para recolhimento das aparas de lápis para canteiros; b) Cesta confeccionada com jornal para guardar materiais diversos; c) Organização de materiais na sala de aula; d) Cesto de lixo confeccionado com jornal; e) Espelho na sala multifuncional; f) Sala de música; g) Área de educação física; h) Campo de futebol; i) Ginásio aberto para educação física

Fonte: Arquivo das autoras

\section{Arquitetura: espaço que expressa a dimensão estética}

Na maioria das vezes, o espaço arquitetônico apresenta características elaboradas por profissionais que pensaram a escola como espaços similares: prédios com a formação de quadrado e o pátio no centro, salas com janelas na parte superior da parede e um porta para o acesso. Estruturas semelhantes que abrigam grupos culturais com características singulares. Notamos a presença de alguns aspectos referentes à 
pintura e a organização das áreas, orientadas pela gestão municipal, mas com algumas características próprias introduzidas pelo coletivo de pessoas da escola. A criatividade da comunidade escolar em alterar os espaços, em inserir o plantio de árvores nativas em meio a brita, na construção de uma casinha com garrafas pets no pátio, evidenciam uma identidade local.

Fig. 7 - Arquitetura da escola

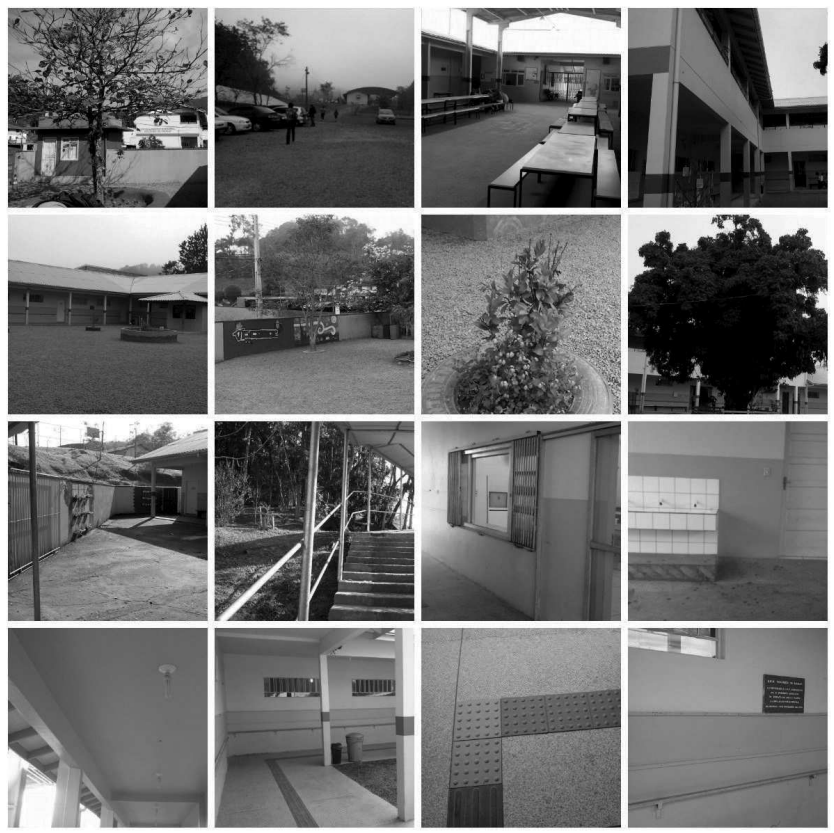

a) Entrada da escola pelo estacionamento; b) Estacionamento; c) Área interna do pátio; d) Espaço físico do prédio; e) Área externa pátio; f) Muros pintados com grafite pelos estudantes;g) Reutilização de pneu como canteiro; h) Árvore no pátio externo; i) Fundos da cozinha; j) Escada para acesso a quadra esportiva; k) Entrada da cozinha; 1) Rampa de acesso aos banheiros; m) Lâmpadas econômicas; Mobilidade: n) Corredores da escola; o) Piso tátil, p) Corrimões nos corredores.

Fonte: Arquivo das autoras

A escola não se torna 'verde' simplesmente pelo fato de economizar energia, coletar baterias e selecionar o lixo, mas no aprendizado que os estudantes fazem com essas atividades. Uma aprendizagem para além da sala de aula, a cultura da sustentabilidade vivida no pátio escolar (LEGAN, 2010).

A mobilidade dos que frequentam os espaços contam com piso tátil nos cor- 
redores, corrimões e nos banheiros rampas para o acesso. As escadas que conduzem ao bosque e as quadras possuem corrimões e cobertura, em caso de cadeirantes o acesso necessita ser pelo pátio do estacionamento. Há no prédio luzes brancas que permitem economia de energia e iluminação clara aos estudantes, câmeras monitoram a vivência escolar no pátio, controle entendido como segurança no trânsito da comunidade escolar no prédio interno. Os ambientes físicos e como inferem psicologicamente nos estudantes, necessitam ser definidos reciprocamente. Na medida em que oferecem uma sensação de segurança proveniente da recepção positiva e valorização, oportunizam o desenvolvimento das relações. Para Rinaldi (2012) a reformulação do conceito e reorganização da arquitetura da escola, dos espaços e formas de conexão, assim como a capacidade de aceitar e apoiar tanto o 'eu' quanto o 'nós', o pequeno e o grande grupo, a memória individual e coletiva. Um sistema que estimula o desenvolvimento de relacionamentos e comunicação entre estudantes, professores e pais.

\section{Escola sustentável: espaço que ensina criativamente}

Compartilhamos com Vieira, Tomio e Pukall (2014, p. 275) a compreensão de que em uma escola sustentável é necessária:

[...] nossa observação atenta do uso que os sujeitos da escola fazem dos ambientes, bem como projetar um espaço neste contexto é um processo altamente criativo, não apenas em termos de pedagogia e arquitetura, mas, também, no desenvolvimento cultural e de uma experimentação sociopolítica dos participantes, 'na medida em que esse momento (projeção) e esse lugar (a escola) poderiam ser experienciados não como o tempo e o espaço para reproduzir e transmitir conhecimentos já estabelecidos, mas como local para a verdadeira criatividade' (RINALDI, 2013, p. 122).

Nesta direção, a aprendizagem dos estudantes no movimento do tempo e espaço da escola sustentável, também, considera aspectos como o reaproveitamento de materiais com destinos apropriados e um aproveitamento dos recursos naturais.

Se alguém decide ir ao banheiro é, também, um momento de aprender. Bilhetes confeccionados pelos estudantes alertam para o desperdício da água e no canto há uma caixa de papelão informando: "guarde aqui o rolinho do papel higiênico". 
A água da chuva captada pelas calhas escoa até um reservatório de água, que depois abastece o jardim elaborado no formato de Pegada Ecológica (pé humano), em frente a cozinha. No parque percebe-se a presença da reutilização de vários materiais como carretéis de madeira, utilizados antes para o transporte de fios elétricos, agora muda de sentido ao ser mesa. Os pneus tanto servem para estruturar canteiros como na estrutura de obstáculos no parque, representando degraus de uma montanha, caminhos a serem percorridos pelo equilíbrio de andar sobre eles, outros que servem de descanso para que as crianças sentem e contemplem a fauna do local. A ação desenvolvida por indivíduos conscientes das reações provocadas no meio suscita a responsabilidade no uso dos elementos naturais e culturais, em saber utilizarem sem esgotar. Isso vai ao encontro do que discute Sauvé (2000) uma comunidade que sustenta seu modo de vida com responsabilidade, consegue sobreviver em conformidade com o ecossistema, sobrevive com os recursos que dispõe e possibilita um desenvolvimento econômico consciente que reflete sobre as riquezas e fragilidades que dispõe, trabalha em prol de uma comunidade sustentável.

A variedade da flora comporta frutos e flores, como a bananeira, a laranjeira e a planta ornamental repleta de sementes coloridas. Convidam a presença de insetos como borboletas, abelhas, formigas e outros animais. Na represa formada por uma fonte de água, girinos e peixes podem ser investigados pelos estudantes. A manjerona em flor presente na saída da cozinha emite um odor intenso, fresco, que lembra infância. Espaços de aprendizagem, de observação de um meio cuja sobrevivência está intrínseca as estações e movimentos da Terra.

Em uma das saídas da escola, pela porta da cozinha, presencia-se uma explosão de odores e cores do jardim biodiverso organizado pelo coletivo da escola. Um lugar que encanta pela mistura de plantas em um canteiro no formato de uma pegada humana, habitada por chás, flores e hortaliças. A água que irriga o local provém da captação sustentável das calhas dirigidas a uma caixa de água, por meio de uma torneira, tem-se como molhar as plantas. 
Fig. 8- Escola sustentável
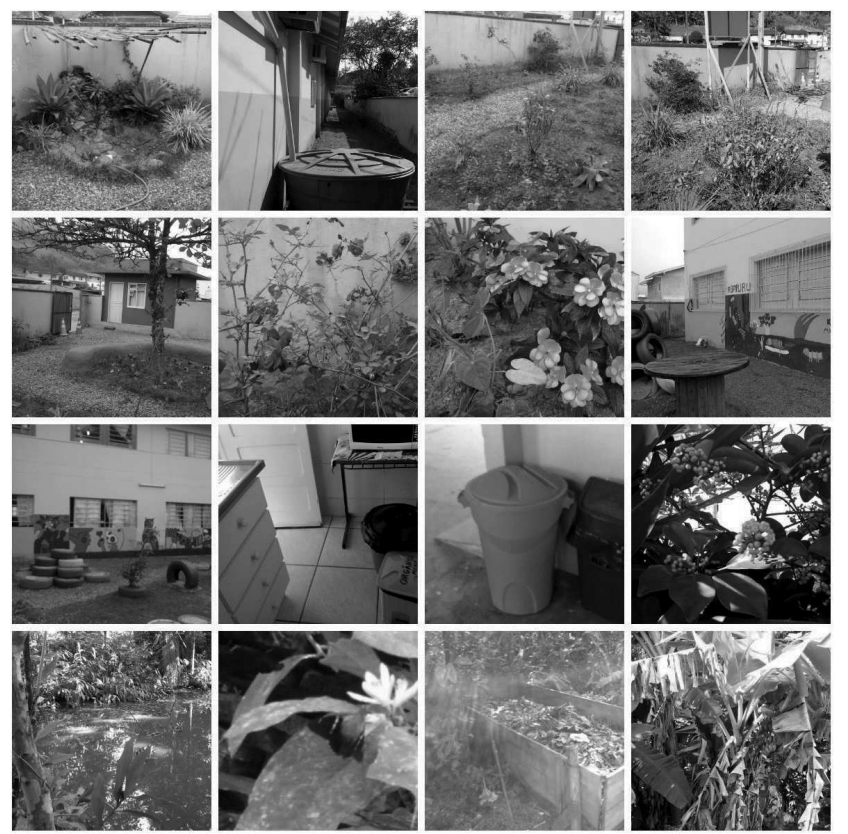

a) Canteiro fundos cozinha; b) Reutilização da água da chuva com pequena cisterna; c) Jardim biodiverso em formato de pegada ecológica; d) Cantinho dos Temperos e aromas; e) Banco de adobe embaixo da árvore; f e g) canteiro de rosas e mimosas nos fundos da cozinha; h) Reutilização de carretéis de madeira no parque; i) Reutilização de pneus no parque; j) Coleta de materiais orgânicos na cozinha; k) Coleta de materiais corredores da escola: orgânico e inorgânico; l) Árvores floridas; m) Pequena lagoa; n) Insetos que vivem na escola; o) Composteira; p) Bananeiras

Fonte: Arquivo das autoras

Espaço cuidadosamente organizado com canteiros na entrada da porta, um banco em formato de ferradura construído juntamente com os estudantes circula um sombreiro. Esse banco foi elaborado com a técnica de adobe - tijolos com barro, água e estrume. O clima local chuvoso e úmido não favoreceu a conservação do banco, o que levou a escola revesti-lo com cimento. Mas o local abriga os estudantes em momentos de leitura e conversações junto com os professores, estes também organizam e cultivam as plantas no canteiro em formato de Pegada Ecológica. O principal objetivo da educação para a sustentabilidade consiste na criação de um meio ambiente sustentável, onde as pessoas possam viver e trabalhar de forma que o desenvolvimento econômico 
e social sejam dependentes um do outro. A interação entre esses aspectos incide no aumento de qualidade de vida (LEGAN, 2010).

$\mathrm{Na}$ experiência de pesquisa, ao (com)viver em espaços de uma escola sustentável, ao sairmos pela porta da escola percebemos ainda as plantas que nascem por meio das sementes levadas pelo vento, do pólen transportado pelas borboletas e outros insetos, na procriação dos sapos e rãs na pequena lagoa existente no terreno da escola, no pássaro que zela por seu ninho no campo de futebol, nos frutos que brotam das árvores... processos naturais inerentes a vontade humana, mas que sofrem as influências de suas ações, quando resolvem valorizar e cuidar dos espaços naturais para fins de aprender e desenvolver em práticas colaborativas e criativas. Nesta escola tem tudo isso compartilhado pelo seu coletivo como um habitat, espaço educador sustentável e criativo.

\section{Considerações finais}

As escolas sustentáveis podem ser vistas como um meio de se repensar o modo como as pessoas relacionam-se com o ambiente, consigo e com os outros em seus tempos de aprender. Novas relações com a natureza incidem reflexões no compromisso ético que considera tanto as necessidades de sobrevivência das pessoas quanto da natureza, suscitam o respeito pelas formas de vida que convivem objetivando a harmonia entre os pares. O habitat da escola, espaço quando sustentável e criativo integra a participação ativa dos estudantes, professores, gestão e pessoas da comunidade. A qualidade do habitat incide nos espaços de aprender da escola, na organização física dos elementos que fazem parte do cotidiano nos seus aspectos mais diversos e integrados, desde a organização do pátio até o destino das aparas dos lápis pelos estudantes.

Observamos que o espaço físico, planejado com uma intencionalidade socioambiental e cultural, é espaço de aprender de toda comunidade escolar. Desta forma, o que presenciamos durante a nossa investigação na escola deixa implícito que não há a necessidade de mudanças radicais para se pensar em espaços físicos que possibilitem a integração social, o pensar sustentável. Mas, ao contrário, a vontade de um grupo que estabelece redes de contato, que assume o compromisso de uma escola em suas funções educativas, em que a cooperação, a solidariedade e o convívio e sustentável sejam norteadores dos processos de ensinar com criatividade.

A partir da iniciativa da equipe gestora, em conjunto com o corpo docente, construíram um local com múltiplos espaços que nos remetem a sentidos diversos. 
Espaços que recebem com acolhimento, promovem uma abertura para que a comunidade local possa interagir no ambiente escolar. Pelos corredores da escola os espaços permitem aos estudantes momentos de descanso, leitura e encontros. No entorno da estrutura física espaços que expressam a vontade de estar junto à natureza, com as hortas e a preservação do bosque servem de espaço de desenvolvimento da criatividade nas práticas educativas inovadoras presentes nos projetos desenvolvidos pelos estudantes.

Observamos que uma escola sustentável no planejamento de seus espaços físicos pode contemplar: Espaços de convivência e cultura que possibilitam e favorecem a mobilidade, acessibilidade, organização e compartilhamento do conhecimento com diferentes manifestações; Espaços como conteúdos educacionais; Espaços hospitaleiros, para receber o outro; Espaços para diferenças, singularidades, particularidades de cada um; Espaços que ensinam; Espaços para o social; Espaços que documentam e Espaços que expressam a dimensão estética.

Ao final de nossa caminhada pela escola percebemos, pelo olhar investigativo e contemplativo, um exemplo de colaboração e integração entre os espaços de aprendizagem e convivência, espaços constituídos em harmonia com a arquitetura e a natureza, espaços inspiradores para aprender conceitos dos diferentes componentes curriculares, praticar habilidades e vivenciar atitudes na direção de uma compreensão de si, do e com o outro, no mundo.

\section{Referências}

ACTA DE CONSTITUICIÓN RIEC. Universidad de Barcelona: Barcelona, 2012. Disponível em <http://escuelascreativas.com>. Acesso em 20 de dez, de 2015.

ADRIANO, G. A. C.; TOMIO, D. Investigar e aprender em espaços educadores sustentáveis de uma Escola pública. In: XII CONGRESSO NACIONAL DE EDUCAÇÃO - EDUCERE.., 2015. Anais... Curitiba: Pontifícia Universidade Católica do Paraná, 2015. p. $237557-23770$.

BLUMENAU. Prefeitura Blumenau. Bairro Itoupava Central. Disponível em $<\mathrm{http} / / /$ www.blumenau.sc.gov.br/secretarias/secretaria-de-planejamento/pagina/historia-sobre-municipio/divisa-administrativa-bairros/bairro-itoupava-central-seplan>. Acesso em 16 de nov, 2016 
BRASIL. Vamos Cuidar do Brasil com Escolas Sustentáveis: educando-nos para pensar e agir em tempos de mudanças socioambientais globais. Brasília: Ministério da Educação - Secretaria de Educação Continuada, Alfabetização, Diversidade e Inclusão, 2012.

BRASIL, Lei $\mathrm{n}^{\circ}$ 12.187, de 29 de dezembro de 2009, que Institui a Política Nacional sobre Mudança do Clima - PNMC. Disponível em <http://www.mma.gov.br/clima/ convencao-das-nacoes-unidas $>$. Acesso em 20 de set, 2015.

BRASIL. Ministério do Meio Ambiente. Convenção-Quadro das Nações Unidas sobre Mudança do Clima (UNFCCC). Disponível em: <http://www.mma.gov.br/clima/convencao-das-nacoes-unidas $>$. Acesso em 20 de set, 2015.

BRASIL. Manual das Escolas Sustentáveis: Resolução CD/FNDE no 18, de 21 de maio de 2013. Brasília: Ministério da Educação; Secretaria de Educação Continuada, Alfabetização, Diversidade e Inclusão; Diretoria de Políticas de Educação em Direitos Humanos e Cidadania; Coordenação-Geral De Educação Ambiental, 2013.

CEPPI, G.; ZINI, M. (Orgs.). Crianças, espaços e relações: como projetar ambientes para a educação infantil. Porto Alegre: Penso, 2013.

EBM VISCONDE DE TAUNAY. Projeto Político Pedagógico. Blumenau, 2013. (mimeo).

GANDINI, L. Espaços educacionais e de envolvimento pessoal. In: EDWARDS, C; GANDINI, L.; FORMAN, G.. As cem linguagens da criança: a abordagem de Reggio Emilia na educação da primeira infância. Porto Alegre: ARTMED, 1999.p. 145-158.

LEGAN, L. Criando habitats na escola sustentável: livro do educador. São Paulo: Ecocentro IPEC; Programa Habitats; Imprensao oficial, 2010.

RINALDI, C. O espaço da infância. In: Diálogos com Reggio Emília: escutar, investigar e aprender. São Paulo: Paz e Terrra, 2012. p. 145-164.

SAUVÉ, L. A educação ambiental: uma relação construída entre a escola e a comunidade. Montréal: Projeto EDAMAZ; UQUAM, 2000.

TOMIO, D. Educação Ambiental Formal. In: WUO, A. S. (Coord.). Proposta Curricu- 
lar de Santa Catarina- formação integral na Educação Básica: Diversidades. Blumenau: Universidade Regional de Blumenau, 2016. [mimeo]

TORRE, S. de la.. ZWIEREWICZ, M.. Uma escola para o século XXI: escolas criativas e resiliência na educação. Florianópolis: Insular, 2009.

TORRE, S. de la; SILVA, V. L.S.. ECOFORMAÇÃO E TRANSDISCIPLINARIDADE NA REDE DE ESCOLAS CRIATIVAS. Dynamis, Blumenau, v. 21, p.15-30, 2015. Disponível em: <http://proxy.furb.br/ojs/index.php/dynamis/article/view/5169>. Acesso em: 13 de fev. 2016.

TRAJBER, R.; SATO, M. Escolas sustentáveis: incubadoras de transformações nas comunidades. Revista Eletrônica Mestrado Educação Ambiental. v. esp., set. 2010. Disponível em: < http://www.seer.furg.br/remea/article/viewFile/3396/2054>. Acesso em: 10 de mar. 2016.

VIEIRA, B.; TOMIO, D.; PUKALL, J. P.. A construção de uma horta mandala na escola: um projeto criativo de espaço ecoformador. In: SCHROEDER, E.; SILVA, V. L. de S. Novos Talentos: Processos educativos em Ecoformação. Blumenau: Editora Legere, 2014.

Recebido em: 15 abril 2016.

Aceito em: 28 abril 2016. 